\title{
Love Has (NO) Boundaries: Researching a Sexual Taboo
}

\author{
Dafna Shir-Vertesh ${ }^{1}$ \\ ${ }^{1}$ Department of Sociology-Anthropology, Ben-Gurion University, Israel \\ Correspondence: Dafna Shir-Vertesh, Department of Sociology-Anthropology, Ben-Gurion University, POB 653, \\ Beer-Sheva 84105, Israel. Tel: 1972-52-448-4844. E-mail: dafnash@bgu.ac.il
}

Received: February 10, 2013 Accepted: February 23, 2013 Available online: February 28, 2013

doi:10.11114/ijsss.v1i1.63

URL: http://dx.doi.org/10.11114/ijsss.v1i1.63

\begin{abstract}
Sexual and emotional attraction humans feel towards animals, also known as zoophilia, is perhaps the most controversial facet of human-animal relationships. In this article I explore this seemingly ultimate transgression of interspecies boundaries and probe the Israeli cultural encounters with it. I discern how the stated concerns for normative sexuality and animal rights masquerade the underlying factors in the zoophilia taboo, and reveal the cultural implications of human-animal sexual love in Israel. My fieldwork reveals not only the limits of acceptable human-animal love, but also the limits of legitimate research, and the consequences entailed for those who resolve to challenge them.
\end{abstract}

Keywords: Zoophilia, Israel, Taboo, Sexuality, Fieldwork

\section{Introduction}

In this essay I contend with the complexities that arise in the attempt to tease out why sexual love of animals remains such a persistent, perhaps ultimate, taboo. Most of us do not think of sexual contact when we think of affection towards animals, yet these kinds of relationships have been a frequent subject in art, literature, and fantasy. Inter-species sexual relations have been documented throughout the ages as a significant part of some human interactions with animals (Taylor 1996; Dekkers 1994; Gregersen 1983; Liliequist 1988 in: Miletski 1999; Waine 1968, in: Miletski 2005).

This physical and sexual affinity people have felt towards animals is one of the most complex and certainly the most contentious aspect of human-animal relationships. Sexual couplings of humans and animals are condemned by many people from different cultures and religions as unnatural, filthy, even satanic, acts performed by a sick minority, a sexual pathology (although they are no longer psychiatrically defined as such under the DSM-IV and DSM-IV-TR). ${ }^{i}$ While there are cultures which do not hold to this adamant outlook, most societies view sexual relations with animals as a cardinal sin or perversion (Dekkers 1994; Miletski 2002; Miletski 2005), one of the last persevering taboos (Beetz 2005b). ${ }^{\text {ii }}$

\subsection{Research Scope and Objectives}

In the last decade or so, I researched human-animal boundaries and emotions in Israel. As part of my quest to prod the human-animal divide, I explored this seemingly ultimate transgression of interspecies boundaries and probed the Israeli cultural encounters with human-animal sexual relations. Specifically, I focused on reactions to zoophilia - the affinity, attraction or sexual attraction of a human to a non-human animal. More than just a sexual act with animals (usually defined as bestiality or zooerasty), zoophilia includes an emotional attachment to the animal (Beetz 2002; 2005a; 2005c; 2008; Kurrelgyre 1995, in: Miletski 2002; Miletski 2002). I aimed to analyze the Israeli engagement with zoophilia and discern how the stated concerns for normative sexuality and animal rights masquerade the underlying factors in the zoophilia taboo, revealing the cultural implications of human-animal sexual love in Israel.

In the three years of my ethnographic research on the topic (2004-7) I was showered with a multitude of intense reactions to my study, ranging from humor and ridicule, through disregard to outright slander. At the same time, these disparaging reactions were accompanied by a strong interest in zoophilia. I was approached by the Israeli media and interviewed for a newspaper and for a television segment; Internet postings dealing with my study received many "hits" and responses. 
In this article I decipher the conflicting reactions Israelis pose to human-animal sexual relations, and address three main categories these reactions fall into: humor, disgust, and lashing out. Through these categories I show how the breach of humanness comprises the main threat in zoophilia, rather than the breach of religious tenets or animal rights. My fieldwork reveals not only the limits of acceptable human-animal love, but also the limits of legitimate research, and the consequences entailed for those who resolve to challenge them.

\subsection{Boundaries and Sexual Taboos: The Condemnation of Zoophilia in Israel}

The pervasiveness of zoophilia and bestiality in Israel can only be guessed at, as no research has ever been conducted on the subject. Some Israelis with whom I have discussed the topic have shared stories of bestial acts they have heard of, and though these stories do not provide us with evidence of the occurrence of zoophilia and bestiality in Israel, they confirm that zoophilia is perceived as taking place in Israel. It is this perception that is relevant when dealing with the cultural attitude towards sexual relations with animals, rather than the actual statistical data.

The exploration of zoophilia and transgressing human-animal relations in Israel exposes the still significant although occasionally challenged - religious tenets and cultural taboos at its Jewish base. The original prohibition against zoophilia in Judaism, like the prohibition against animal worship, was intended to differentiate Jews from others, and to create a distinctive identity (Davies 1982). As declared in Leviticus in regard to bestiality: "it is confusion” (18:23). ${ }^{\text {iii }}$ Indeed, Douglas’s (1966) analysis of Leviticus maintains that taboo protects distinctive categories by confronting threatening ambiguity.

The cultural perceptions of sexuality in Israel are influenced by additional factors as well, such as global (or Western) trends of sexual liberalism and tolerance. Yet while there is generally a growing lenience towards homosexuality in Israel and in many places around the world, this liberalism does not extend to zoophilia. In fact, the change in the perception of zoophilia and bestiality is going in the opposite direction. These acts are decreasingly associated with homosexuality and 'crimes against nature', and instead are now associated with pedophilia and 'crimes against the helpless', or those unable to consent (Beirne 2000; Kolb \& Brodie 1982, in Cerrone 1991; Nagel 2002). Sexual relations with animals, while still attacked by religious and conservative groups as unnatural, are under renewed attack from animal rights activists around the world who see sex acts as constituting physical and sexual abuse of the animal.

Legally, bestiality and zoophilia are not mentioned specifically in any law in Israel. Until 1977 they were covered under chapter 17 of criminal law order of 1936, a British codex based on English law, as "crimes against morality". Today, bestiality and zoophilia would probably be tried under the animal rights laws of 1994. However, no one has been tried in Israel (at least not since 1950) for having sexual relations with an animal. This should not be seen as tolerance of these acts, but rather demonstrates two separate matters: first, a relative lack of concern for animal rights, as is evident in the small number of laws regarding the topic and the few cases tried under these laws (Haaretz, 29/4/2007 1B); second, and more important, a tendency to disregard of the phenomena of bestiality and zoophilia and almost no public awareness that sexual relations with animals are more than a rare oddity.

\subsection{Interrogating the Erotic Hyphen between Humans and Animals}

Human-animal sexual relations are a fundamental sexual taboo in many cultures, yet unlike, for example, the incest taboo, they have seldom been studied by social scientists (Beirne 2000). It seems, however, that the topic has received more attention in the last decade or so (Beetz 2002; 2005c). Peter Singer, the philosopher renowned for his work on bioethics, stirred up the topic in his controversial piece titled "Heavy Petting". In the short essay Singer claims that sex with animals does not necessarily involve cruelty and that "occasionally mutually satisfying activities may develop" (2001). Subsequently, psychologists and sex researchers have conducted research focusing on the species and kinds of practices involved (Beetz 2002; Miletski 2002; Williams and Weinberg 2003), the motivations of zoophiles (Beetz 2002; Miletski 2002; Williams \& Weinberg 2003), their personality and mental health (Beetz 2002; Miletski 2002), and their sexual orientation (Miletski 2002). Most recently, writers from fields such as feminist theory (Grebowicz 2010), education (Kahn 2011), Philosophy (Bakke 2009) and anthropology (Cassidy 2009; Shir-Vertesh 2008) try to unravel the cultural contextualization and constructions of the interspecies sexual taboo. Grebowitz (2010:12), for example, calls to interrogate, historicize, and unhinge the connections between animality and sexuality "in an effort to denaturalize exploitative sexual practices". Cassidy (2009) initiates such an attempt, as she claims: "Conflicting and contradictory relationships with animals in Euro-America are the backdrop to both the emergence of zoosexuality and the determination to legislate against bestiality" (p. 96). 


\section{Methods}

How does one study the cultural contextualization of a sexual taboo? My inquiry into zoophilia began in front of a computer screen. Attempting to rebuff accusations of insanity and perversion, zoophiles have formed an internet community where they get in touch with each other and (usually anonymously) express their thoughts and feelings on a variety of topics. From several forums and discussion groups that I found, I chose one that seemed serious and comprehensive, and announced my presence by posting a notice. The responses I received initiated a long, intimate and reciprocal dialogue with members of the community.

Aiming to explore reactions to zoophilia in Israel and to understand the extent of its taboo, I turned once more to the internet, analyzing discussions of sexual relations with animals, especially in Hebrew sex sites, as well as internet debates following my publications. Despite certain difficulties, research can and does benefit from this 'virtual method'. To begin with, the internet provides a means to access reactions to a phenomenon which it would otherwise be very difficult to obtain. The simple fact of the matter is that Israelis very rarely launch into a conversation about zoophilia unless somehow triggered to do so. When these conversations are conducted face to face, as will be illustrated below, people might feel reluctant to convey their uncensored thoughts on such a charged topic. The anonymity of the internet provides comfort and openness as well as possibilities for emotional outlet.

At the same time, cultural reactions to erotic love of animals did become evident when discussed in personal exchanges, in the classes I taught, and after the talks I gave in conferences, as well. The combination of these different settings enabled me to observe responses to zoophilia and zoosexual practices, both non-mediated in face-to-face situations, and in (almost) uncensored internet talkbacks.

In order to explore reactions to a rarely discussed taboo, my research plan had to be flexible and involved using a multitude of perspectives and strategies. This included turning to Israeli "pop culture", including jokes, commercials and internet talkbacks. Popular culture manifestations that make people laugh or enraged can inform us of the ways people incorporate pop culture into their experiences and construct their own interpretations from them. This became clear in personal conversations I held on zoophilia, in reactions to media depictions and in observations of classroom and conference attendees.

\section{Results}

\subsection{Personal Confrontations and Reactions}

While zoophilia is rarely discussed openly in everyday conversations in Israel, stories of sexual escapades with animals are told, mainly involving young boys living on a Kibbutz, Bedouins, or soldiers. For example, quite a few members of Kibbutzim swear they found condoms in inhabited animals' stalls (mainly cows and sheep). As a native Israeli, several of these (sometimes mythical) tales are familiar. These stories are usually told as an esoteric and amusing anecdote, as demonstrated in the following joke, related to me by a student of mine:

A young man joined shepherds for the first time, herding their sheep on the mountains in the summer. After a few days he felt 'the urge' and asked someone what is done in these situations. "Grab a sheep and enjoy," he was told.

The guy grabbed a sheep and was met by a surge of laughter. "What - did you fool me? You don’t really screw sheep?" he asked, and the rest answered: "Ya, we all screw sheep, but not the ugliest one in the herd!"

Humor is a common way to deal with zoophilia: most of my students find it hard to hide a smirk, if not a laugh, when they hear that I research this topic. Their initial laughter is often followed by curiosity: many of those who engage in conversations with me on the matter, both in the classroom and in private, are very interested in zoophilia, want to learn more, and present their opinion on it. Usually this opinion includes concern towards the animals involved and their rights.

Other people I come into contact with - in everyday conversations, in conferences, in classrooms - do not feel that this is a topic worthy of rational debate, but rather should be denunciated from the outset. For this reason, their response to my research, as it does not denigrate zoophilia altogether, is often extreme, and often equates me with my research. For example, during one of my classes, I discussed zoophilia and my research with the students. One of my students came to class the following week, raised her hand, and said that her mother insisted she drop the class, after she heard of the topic of the previous lecture. 
The following encounter provides a good illustration of the ways my research on zoophilia is handled within personal discussions and publications. It demonstrates the curiosity combined with revulsion and the questioning of the very legitimacy of the topic (and researcher), as they are expressed towards zoophilia:

I had been in contact with the people working in a project named "Animals and Society" for several years, and published an article on zoophilia in their journal of the same title (Shir-Vertesh 2006). In March 2007 I came to search the project library at the Tel-Aviv University offices for relevant materials.

Sex was much in the news on that day. The Israeli ambassador in El Salvador had just been found lying in the street wearing only sadomasochistic accessories. Hadas, one of the women working in the office, walks in, and before she even greets me, she says: "Apropos Dafna Shir-Vertesh - did you hear of the Israeli ambassador?" "Yes," I turn to her, "but how exactly is it connected to me?" "What do you mean?" she seems puzzled, "Your research..." I think for a split second and understand that she automatically associates me and my research with any form of kinky sex: "My research deals with zoophilia. The ambassador was involved in sadomasochism.” Consequently all those in the office debate what it is exactly that he did and where. I finally go back to the books, when once again Hadas turns to me: "You know - someone cancelled their subscription to our journal following your article. It was the first issue he received, and he immediately called enraged to cancel, saying: 'I can't believe you publish such disgusting things'." "Really?” I find it hard to hide a smile. The others notice my interest and tell me of the many responses to the article, including from their friends: "My friend did not understand why we publish such revolting materials," says Yifat. "She thinks it creates the impression that we encourage such things". "And if Haaretz would publish a piece on a murderer would that mean they endorse murder?” Adva asks. "Of course not," Yifat replies. "It's some issue she [her friend] has with herself, that causes her to be so disturbed by this." Adva turns to me, and says: "I think people are so opposed to the article because it presents things from the zoophiles' point of view”. To this I reply: "I actually feel it doesn't really try to take a stand or say it’s Okay.” "No, no, of course not," Adva is quick to agree, "it just also portrays their side so as to understand the perversion." After a while she adds: "As far as I'm concerned, it's exactly the same as pedophilia, since they don't have the animal's consent." To this Yifat immediately answers: "We don't get their consent for many things! Do animals agree to be eaten, worn, experimented on?" Yes, but it's not the same," Adva objects, sounding unsure. "What is the difference?" I prod, and she answers: "I don't know. It is sexual relations. It's different; we force ourselves on the animal without consent. As far as I'm concerned it's exactly the same as pedophilia."

In this conversation, Adva goes from the springboard of zoophilia to all kinky sex, to harassment, to pedophilia. Interestingly, Adva maintains she sees zoophilia as abusing animals in different ways than other treatments of animals, though it is hard for her to express why, beyond that zoophilia also involves sexual relations. As can be noticed, Adva also compares zoophilia to pedophilia and murder, and discusses it as a perversion, even after reading the article, in which it is defined differently. Hadas's immediate association when she saw me was with a sordid sexual incident. At the same time, these women constantly try to depict themselves as liberal and understanding. Indeed I feel that many people with whom I personally speak try to present themselves as relatively open and liberal, and usually either laugh uncomfortably when confronted with the topic or say they are disgusted by sexual intercourse with animals only because it harms the animals. This theme recurs in all three contexts of this part of the fieldwork, and is discussed in the next sections.

\subsection{Media Depictions and Discussions}

An official administrator's notice in a sex forum, posted in one of the very few threads gently touching on the subject of sexual relations with animals on Hebrew-language internet:

A managerial announcement to all the irritated:

We have received and seen all the requests to delete this thread. The reason it still exists is that the subject brought to light is surely, as everyone agrees, irregular, and yet the phenomenon of sex with animals exists.

And perhaps this is the place to bring into awareness that there are people who have sex with animals, and to clarify the fact that this is unequivocally abuse!!

Yes, this is a very problematic issue and there are people who are not aware that using animals for sex is indisputably animal abuse!

The existence of this thread here perhaps will revive the topic, and who knows? Maybe one day they will be so kind as to formulate a law that enforces it. And even if they don't, at least there will be awareness.

Besides, it is a perversion... 
(My translation, Hebrew source can be found http://forums.nana10.co.il/Forum_59/9/4/3832649.html)

There are a number of interesting matters in this "managerial announcement". The first is that it seems the administrator received quite a few complaints requesting the deletion of the thread. As this is a sex forum dealing with many different sexual inclinations and fantasies, and as the internet medium allows one to simply go to a different thread or page if they feel uncomfortable with the contents, people must have felt quite "irritated" to ask for the removal of this discussion. The thread itself started with the simple question: "I wanted to know, maybe it will sound disgusting, but what do you think of sex with animals? Has anyone tried? Does anyone want to try?” It was not at all explicit or suggestive.

The second issue is that the administrator made a point of emphasizing, and then repeating, that sexual relations with animals unmistakably constitute abuse. Moreover, her hope that this thread will help raise awareness and change legislation seems a little beyond the scope of a sex forum.

Finally, after voicing her position as a universal fact, she concludes by commenting casually ("besides") that zoophilia is a perversion. According to DSM-IV (1994) and DSM-IV-TR (2000), it is not.

This announcement is quite representative of dealings with zoophilia in Israeli internet sites, including sex forums. Although animal-sex and animal-love are hardly discussed, when they are, they are usually presented as harmful, sordid and off limits, although occasionally someone will exhibit curiosity.

Through different forms of media (the combinations of internet, television, and newspaper articles), I was able to further explore the Israeli unease about hitting this cultural nerve. Two commercials that aired on Israeli television in 2007 blurred the border between humorous and curious aspects of zoophilia:

(1) A young man is sitting at the bar in a diner. In the background Bonnie Tyler's song, "Total Eclipse of the Sun”, is playing. Next to him is sitting a goat. ${ }^{\text {iv }}$ The goat winks at him, and a pink neon heart with the word "love" inscribed in it lights up behind them. The man looks adoringly at the goat and smiles.

This meeting marks the beginning of their many escapades together. Finally, the man offers the goat an open Styrofoam box containing a hamburger, in a gesture very reminiscent of a marriage proposal. The goat bleats, hopefully saying yes.

At this point, the man notices his shirt is getting very tight, since all the food they ate together caused him to gain weight. He deserts the goat at the side of the road and drives away, as the goat is waving goodbye with a handkerchief. The narrator: Always stopping for fast food? That's a goat, and it's time to get rid of it." Now you can buy healthy meals at "Yellow".

(2) A man is sitting in a dark kitchen reading a newspaper. Suddenly burlesque music starts playing. The refrigerator door opens; a long cartoon leg appears behind it, followed by the entire body - a distinctly female Jessica Rabbit-esque chicken, featherless, complete with women-like breasts and a hint of female genitalia. The chicken starts dancing erotically with vegetables in her hands as the man looks at her flabbergasted.

At this point his wife and daughter step in, carrying groceries. They can only see the man - his head reached out, his lips slightly open, his eyes closed. The man notices them and smiles apologetically. The narrator: Fantasizing about a good meal? Now from "Mama-Off”vi - chicken and vegetable schnitzel.

Both commercials depict love and desire from the point of view of an anthropomorphized animal portraying the (hu)man's love interest. Both also generated a relatively large amount of responses, especially on internet discussions: as it happens, loving a goat seems to comprise a more acceptably humorous situation than being turned on by poultry.

An Israeli TV magazine named "Rating" (similar to the American "TV Guide”) discussed these commercials separately in its column on commercials. The first column, titled "I want to milk you, goat", deals with the human-goat love story (6/6/2007), and is subtitled "Yellow's new commercial offers the kinkiest love story around”. The column states that Yellow's commercial enters bizarre territories. In an interview between the journalist and the creative vice-president of the advertising agency, they hypothetically continue the 'incident', as a real-life affair that developed between the actor and the goat: "It was impossible to ignore the magical moments between the actor and the goat... I'm telling you, they [female goats] have no boundaries.”

The second column, regarding the seductive chicken, is not as humorous. Published only three weeks later (27/6/2007), it is titled "Screwed a chicken for lunch", vii and subtitled "After the goat in-love, make room for the enticing kuritza". viii The journalist wrote: "There is something disturbing in the new commercial from 
'Mama-Off'... because it looks very convincing... God, she [the chicken] is good... [the actor] wants her bad. And quickly... he is lusting after the animal in a display of over-acting from bizarre territories. Bon Appétit, I lost my appetite."

The Israeli public responded similarly in internet discussions: “...Mama Off will not enter my freezer... Is this what children should see in a commercial?”; "A man fantasizing about a chicken. Sexual innuendoes - sick and disgusting... It's no wonder we have turned into a society of perverts...”; "I don’t understand how sex with animals is supposed to make me buy schnitzel? Think how many years of therapy it will take for that child to erase the image of her father being turned on by a chicken from her mind"; "Mama-Off - congratulations. You have won the most-disgusting-commercial-on-TV award”; “... they made me sick. I'm boycotting their products!”; “...Horrifying” (http://www.ynet.co.il/articles/0,7340,L-3420926,00.html, accessed July 4th 2007); "Death to Mama-Off! I apologize for the harsh response, but it's rare to see such a substandard commercial" (tarbut.nana10.co.il).

It seems that the first "Yellow" commercial, portraying a human-goat love-story, is perceived as humorous, since it does not seem real. The goat was chosen because it is conceived of as a ridiculous love-object. Most people do not feel that attraction to a goat could exist, and therefore find the entire situation, as long as it clearly remains unrealistic, as hilarious. Indeed, the over-the-top kitsch motives - Bonnie Tyler's song, the neon sign - strengthen the notion that this is but a joke. In addition, even in the context of a joke, the goat (ez) is portrayed as intrinsically something that should be abandoned as an excessive burden; the man in this commercial recognizes his error and corrects it. Though the commercial is described as "kinky" and "entering bizarre territories" by the "Rating" columnist (6/6/2007), it does not cross the line, or boundary, if you will, and remains extreme but 'safe' precisely because it is a parody.

While most viewers do not feel the option of being attracted to a goat is relevant to them, the "Mama-Off" commercial tries to change their opinion in regard to poultry. The 'chick' parading before the hungry man really is sexy. It is the realness of the situation, and the actual enticing qualities of the chick, that have produced such strong reactions: the chicken is naked, is long-legged, has breasts and genitalia, and dances very erotically. Viewers could get turned on by this animal, and in a certain way are indeed intended to. The man depicted is an unexpected victim of a sexualized chick's overtures, and is portrayed as susceptible to acting on his sexual fantasies, as other men might be. While the "Yellow" commercial is ridiculously funny, the "Mama-Off" commercial is realistically daunting, and as such, is no longer a joke.

We can also not ignore the fact that "Mama-Off" is selling a food product. Though the association between meat and female sexuality has been explored (Adams 1995), this connection further complicates the transgressing qualities of animal sexuality in this case. According to Shell (1986), pets stand at the intersection between species (human and nonhuman) and between families (kin and not kin). They can therefore be seen as at the crossing-point of incest and eating taboos as described by Leach (1964): they are concurrently at the borderline between family and non-family (beings with whom sexual intercourse would be considered incest and beings with whom it would not be considered incest) and at the border between non-man and man (beings which many be eaten and those which may not be eaten). This dual liminality can explain why the "Mama-Off" commercial is perceived as especially troubling, mainly in a Jewish society where anxieties about food and sexuality are strictly regulated via prescriptive laws and proscriptive taboos.

The Hebrew-language internet proved helpful in observing local reactions to a more methodical discussion of zoophilia as well. The on-line edition of Maariv published in 2006 an article about my study of zoophilia (http://www.nrg.co.il/online/1/ART1/070/940.html accessed April 7 2006). The article describes zoophilia, and presents several ethnographic encounters with members of the zoophile community. It introduces my main argument, that animals' rights or reproductive sexuality are not the only matters at hand when discussing zoophilia as taboo. Compared with other newspaper articles, this one received a relatively large number of reader reactions.

Of the 74 talkbacks, many (30) expressed extreme aversion: “Disgusting - I didn’t even read the article, but it is just sick...” one comments, and another agrees: “Apathy - stupidity... It's horrifying that this disgusting article is trying to portray an approving picture of this awful subject, and what's worse is that some of you are laughing about it. We are not human beings but rather the scum of human kind... Sick in the head! And to the editorial staff - shame on you for the horrifying article. What will your next article discuss? Incest or pedophilia? I wonder in what light you'll present the topic - I hope as positively as this piece."

Beyond the talkbacks that express revulsion and anger towards zoophilia and the article, there are many (25) humorous reactions, which make fun of the possibility of being attracted to an animal: "seeking a tall Ashkenazi seal" or "sensitive, 24, looking for an armadillo for an open yet supportive relationship..." 
Several of the retorts (6), are directed at me personally. As some were rejected and erased by the forum administrator, the following is one of the more benign ones: "To the reporter Dafna Shir - you are simply fucked up!... Next time, my dear, give us an explanation for a father who is raping his little daughters and try to embellish it like you did in the current article. I want to vomit on you! And on the horrifying article!...”

It is important to note that in the article I do not support zoophilia in any way, in fact, I never state my opinion. It is also interesting to note, that this article received 74 responses to date (and continued to get responses almost three years after it was published). An article published in the same site about a father who raped his daughter received 13 talkbacks, and an article on UN soldiers who raped children got four. Though not a valid statistical sample, these numbers suggest that this topic hits a deep cultural nerve, more so than actual stories of pedophilia. Even a report of a father raping his daughter - an example of extreme abusive behavior specifically mentioned in one of the talkbacks - did not evoke such strong reactions.

\section{Discussion}

\subsection{Curiosity, Humor, Disgust, Hostility: (No) Zoophilia in Israel}

The various Israeli settings I explored demonstrate that zoophilia is one "different thing" that people in Israel, on the one hand, are not willing to accept, and on the other, find captivating. At first glance, zoophilia does not 'officially exist' In Israel and is rarely discussed. This silence can be seen as a major comment on the unacceptability of these actions. When the silence is broken, mention of human-animal sex draws strong interest and even stronger reactions. The intense, uncensored, reactions to zoophilia indicate that while most Israelis prefer to ignore the phenomenon, when directly faced with it they find it strikes a chord. Their reactions fall into the three main categories of humor, disgust, and lashing out.

\subsection{Humor}

Restricted subjects, Alford and Alford (1981) tell us, are natural subjects for humor: "Restriction implies order and where there is order, such order can sometimes be violated humorously" (p. 155). In fact, joking is helpful for covert communication on taboo matters since it offers the possibility of commenting on it without a catastrophic degree of social disturbance (Emerson 1969:171). This is due, perhaps, to the role humor plays in the drawing of boundaries between "the normal" and "the abnormal" (Powell 1988:99). When someone states they are "seeking a tall Ashkenazi seal", or laugh at the guy attracted to the goat, they are marking the attraction to the animal as abnormal, outside the realm of acceptable order.

Moreover, the use of humor is a way to deal with threatening situations, and as such reveals and alleviates underlying tensions (Leach 1964). Through jokes people express repressed sexual or aggressive wishes and relieve themselves of their anxieties (Dundes 1987). Smiling, laughing, and cracking jokes, provides an option for people to ease their discomfort when confronted with a taboo, such as zoophilia.

Deckers and Kizer (1975) have suggested the Incongruity Hypothesis to explain humor. According to this hypothesis, it is the unexpected, or surprising, that makes things funny. What makes some of the talkbacks and the joke mentioned above, funny, is the incongruity between the feelings/acts and their object. For example, in the joke about the young man who joins the shepherds and is encouraged to relieve his urges with a sheep, we expect the other shepherds are laughing at him because they are playing a practical joke on him. The unexpected element is introduced when we find out that not only are they serious about him having sex with a sheep, the sheep is so completely transformed into an object of attraction, that they actually differentiate between more and less desirable sheep. The same can be said for comments such as: "sensitive, 24, looking for an armadillo for an open yet supportive relationship...” Here we can see a familiar phrasing, used in personal ads to look for a partner. But instead of a human addressee, we find an armadillo, creating a surprising twist. Once again, these incongruities are intended to remind us that such feelings towards an animal should be shocking, outside our regular logic or moral principles.

\subsection{Disgust}

Disgust and humor share considerable points of contact. The mentioning of certain topics can elicit both disgust and comedy (Miller 1997:ix), and like humor, disgust can convey "a strong sense of aversion to something perceived as dangerous" (ibid:2).

Certain references to zoophilia, such as the article on my research, can elicit both humorous and disgusted reactions. Other instances are much clearer, and educe either comedy or revulsion. As Alford and Alford (1981:155) claim, the fact that certain situations can be treated humorously means that they are not over-restricted. When dealing with zoophilia, the reaction can be humorous if the erotic love of animals is perceived as far-fetched (goat, seal, armadillo), or is deemed a rare and remote phenomenon. But when zoophilia is perceived as real, or too 
close to home, as in the "Mama-Off" commercial (literally displayed in the homes of the viewers), it is experienced as revolting beyond the bounds of decency.

According to Miller (1997), disgust is, above all, a moral and social sentiment, a key element to social control, one that ranks people and things in a kind of cosmic ordering. Thus, disgust is a feeling that has political significance. It can maintain hierarchy, can constitute claims for superiority, as well as be elicited as an indication of the proper placement in the social order (p. 8-9).

When dealing with zoophilia, reactions of disgust are indicative of the very offensiveness of human-animal sexual acts. Again, these acts and feelings are morally inconceivable to the Israeli audience, a danger they want to distance themselves from so as to maintain the social order they know. According to this social order, humans are in a completely separate category from animals, one that is significantly superior. This illuminates the claim that disgust mirrors the human concern to be differentiated from other animals or to not be deemed animals at all (Rozin \& Fallon 1987). In the case of zoophilia, expressions of disgust not only distance one from this perceived danger, but also provides a reminder, both to oneself, and to others, that humans and animals are two distinct categories, that in the hierarchal order animals are inferior, and that the two should never be mixed to the point of confusion.

\subsection{Hostility}

Writing about sex can put you in a dangerous or marginal position. It makes you "morally suspect" (Plummer 1975:4). Others may find your work trivial or funny, but also subversive (Troiden 1987). You may suffer from 'the cognation of stigma', as your intentions are put into question and you are branded as a member of the group under study (Kirby \& Corzine 1981:4). Indeed, other scholars who have researched zoophilia or written about it have been faced with extreme reactions and criticism (Beetz 2005b; Singer 2001). In my case, after being given strange looks during conferences and personal conversations, and also being asked why I chose to investigate such issues, I felt a need to mention, even if only as a joking comment, that my interest in zoophilia is solely research oriented, and that in the privacy of my home I have not developed a unique relationship with my cat. I realize that were I not a relatively 'normative' person, heterosexually married with (then) two children and characterized by an innocent, somewhat-childish face, I would probably have had an even harder time differentiating myself from the community I wished to study.

And still, as the ethnographic examples illustrate, I never completely managed to disassociate myself from the topic I study. Reactions towards my research are often personal, as is demonstrated in the conversation at the "Animals and Society" library, and also often hostile, as can be seen in the talkbacks.

Perhaps the reason for the hostility is that my research is not only about sex, it is about a sensitive taboo. Researching sensitive topics can be deemed threatening in certain situations. Lee (1993), in his book on sensitive research, touches on this point:

[O]ne would most expect research to be threatening within three broad areas. The first is where the research poses an 'intrusive threat', dealing with areas which are private, stressful or sacred. The second relates to the study of deviance and social control and involves the possibility that information may be revealed which is stigmatizing or incriminating in some way. Finally, research is often problematic when it impinges on political alignments, if 'political' is taken in its widest sense to refer to the vested interest of powerful persons or institutions, or the exercise of coercion or domination ( p. 4).

My research on zoophilia is threatening in all three areas. It deals with a private and stressful taboo, one which involves deviancy and stigmatization, and encroaches on the human domination of animals. Yet it should be pointed out that the people threatened by my research topic are not the zoophiles, the so-called deviants whose privacy is being invaded, but rather the Israeli audience, exposed to these secretive, private, stigmatized acts. Still, it seems they felt they were invaded by the very exposure to the topic. This invasion resulted in disgust, and the need to be removed from the peril of contamination.

Disgust is contagious - touching something disgusting makes others disgusting themselves (Rozin \& Fallon 1987). For this reason, by studying disgust one risks contamination (Miller 1997:711). My research on the perceived revolting practices of zoophilia made me repulsive, and therefore dangerous and contemptible.

\subsection{Transgressing Bounds of Humanness}

Ranging from laughable to reprehensible, zoophilia does not leave Israelis indifferent. Both the tendency to ignore the subject and the more overt reactions, strengthen the view that human-animal sexual love is implausible and impossible, and that those who have sexual relations with animals, and to some extent those who research it, are troubled, sick and indecent. 
As we ponder the zoophilia taboo, it is impossible to ignore the fact that zoophilia, quite obviously, is about sex, and this aspect plays an important part in the squeamish reactions Israelis exhibit towards zoophilia. As Queer theorists have elucidated, sexuality is a field of power (Bunzl 1997:133) that excludes otherness (Phelan 1989). Humans deal with various animal-related issues in an already extremely anthropocentric viewpoint, and once sexuality is implicated, responses turn less rational and more affective and moral (Beetz 2005a), especially in a dominantly heterosexual space (Butler 1990).

Sexual intercourse with animals is rejected because it treats human sexual activity as similar to the coupling of animals, as detached from the articulation of a comprehensible common good, and so treats human sexual life as merely physical (Finnis \& Nussbaum 1993:12). Having sexual relation with animals can be perceived as demoting humans to being animals themselves, seeking immediate satisfaction without thinking of the consequences. Bestiality and zoophilia are therefore considered to be the lowest category of sexuality, seeing that it obscures the boundary that ties humans exclusively to each other. This form of sexual relations literally blurs the distinction between the human and the animal, as both participating parties are physically joined together. It is this notional and biological proximity between the human and the animal that makes zoophilia so threatening; the fear of losing our distinctiveness as humans is very real. Thus these sexual relations are perceived as inherently wrong and are strongly condemned. It seems that mating outside the human species is not as much a biological issue as it is a cognitive and emotional one. It is so troubling because it disturbs our definitions of species-self, of humanity, and in the case of Israel - of Jews, as above and apart from all other living creatures.

While Haraway claims that the blurring of different boundaries can be, and is, celebrated (2000), it also arouses anxiety (Douglas 1966; Fuss 1996) and is condemned and punished when conceived of as a danger. This is especially true in the Jewish tradition and in Israel. When dealing with zoophilia, the sense of danger in Israel is clear. This can be seen when we return to the internet reactions to my research (http://www.nrg.co.il/online/1/ART1/070/940.html accessed April 7 2006). These referred to zoophilia as "sick" (commented by a respondent who did not even bother to read the article before he passed judgment), "horrifying", "repulsive" and "disgusting" to the point of "vomiting". Though many responses seemingly deal with the violation of animal rights, the 'repulsiveness' seems to have less to do with the matter of harming animals and more to do with threats to humanness. In these reactions there are 51 references to the words 'enosh' and 'adam', both meaning 'man' or 'human', and 'enoshi', or 'being human', compared with only 22 references to 'xaiot' or 'ba'alay $x a$ 'im' - meaning animals. The preoccupation is therefore rather with the violation of the 'human'.

The infringement of the perception of 'what it means to be human' is moreover bolstered as the discernment of 'the animal' is being challenged. In distinction to the parent-child bond, which is by its makeup a one of inequity, erotic love is love between equals (Fromm 1956). For this reason, companion animals can be loved as family members and babies (see Shir-Vertesh 2008; 2012), but not as mates. As sexual partners, mature animals can be conceptually transformed into our partners (Bakke 2009:222), our equals, both emotionally and physically, or can at least be viewed as competent adults, mature, sexual creatures with needs and wants. Treating the animal as a sexual partner, able to consent to having a relationship with humans and even initiating it, can actually be seen as an empowering perspective of the animal. From this standpoint, this form of love towards animals acknowledges them as worthy of love in their own right and not as human-like love objects

Most humans, and, specifically those Israeli families who keep pets (see Shir-Vertesh 2012), do not want to view their animals as sexual creatures - they neuter and spay them, hose them down while in the act or at least laugh uncomfortably. But, in fact, there is a culturally acceptable way for animals to be sexual - when they are dead. There is an erotic charge in fur and leather, men feel masculine in leather and women feel feminine in fur and feathers (Dekkers 1994). Animals can be sensual, as long as human dominance is preserved.

Thus, while it has been claimed throughout history that zoophilia infringes on the natural order, it is rather the breach of human categories that makes it taboo in Israel; the human perceptions not only of what it means to be human, but also of what it means to be an animal - inferior, helpless, dependent, voiceless. The Israeli reactions reinforce the barricades and prove, once again, that the borders are salient. There is nothing cute, endearing or admirable in inter-species sexual relationships, for there is no anthropomorphizing, no pretending that the animal is just a temporary replacement for the real and aspired thing; the chicken, goat, dog or cat is loved precisely for its animalness. Human-animal boundaries are neither played with nor blurred - they are transgressed: lines are crossed with interspecies unions of love. Thus the fear becomes too real and imminent - the animal and the human categories can lose the distinction between them when animals are no longer treated as inferior to humans. 


\subsection{Conclusion: Researching a Sexual Taboo}

As this analysis of zoophilia demonstrates, the comprehension of humanness in Israel is again formulated through, and against, 'the animal other'. This sexual taboo remains a continual threat not only because it challenges categories, but mainly because it undermines the category - that of humanity itself. Zoophilia is an ultimate transgression of human boundaries, and as such defies the very cultural perceptions of 'who we are', and what it means to be human in Israel.

Simultaneously researching the zoophile internet community and reactions to my research, I am able to observe a dialogue between those practicing human-animal sexual relations, and the reproachful Israeli public. Flexibly expanding the 'field' to include internet discussions and other media depictions, university classes, conferences, and personal meetings, a glimpse into the otherwise hidden thoughts and feelings Israelis have towards interspecies sexuality and love is obtained.

Through this exploration, I am also confronted with what people think of my choice to research not only a sensitive topic, but one involving sexuality, not to mention a taboo. I discover that all reactions to the topic of my research are applicable to me as well. Although the study of zoophilia and cultural reactions to it comprises just one part of my research on human-animal loving relations, it became the one I am most associated with (as of now), or notorious for.

Whether through disregard, ridicule, rejection, or legislation, the message is conveyed rigidly: sexual loving relations with animals are not legitimate or 'normal' in Israel. The exploration of these transgressed lines is not acceptable. Those that engage in these relations or those that discuss them without rejecting them completely should be put in their place and sanctioned.

\section{Acknowledgements}

I would like to thank Professor Fran Markowitz for her influential guidance in this research project.

\section{References}

Adams, C. J. (1995). Woman-Battering and Harm to Animals. In C. J. Adams \& J. Donovan (Eds.), Animals and Women: Feminist Theoretical Explorations (pp. 55-84). Durham: Duke University Press.

Alford, F., \& Alford, R. (1981). A Holo-Cultural Study of Humor. Ethos, 9(2), 149-64. http://dx.doi.org/10.1525/eth.1981.9.2.02a00030

Bakke, M. (2009). The Predicament of Zoopleasures: Human-Nonhuman Libidinal Relations. In T. Tyler \& M. Rossini (Eds.), Animal Encounters (pp. 221-42). Leiden: Brill.

Beetz, A. M. (2002). Love, Violence, and Sexuality in Relationship between Humans and Animals. Dissertation, Fridrich-Alexander-University.

Beetz, A. M. (2005a). Bestiality and Zoophilia: Associations with Violence and Sex Offending. In A. M. Beetz \& A. L. Podberscek (Eds.), Bestiality and Zoophilia: Sexual Relations with Animals (pp. 46-70). Ashland: Purdue University Press.

Beetz, A. M. (2005b). New Insights into Bestiality and Zoophilia. In A. M. Beetz \& A. L. Podberscek (Eds.), Bestiality and Zoophilia: Sexual Relations with Animals (pp. 98-119). Ashland: Purdue University Press.

Beetz, A. M. (2005c). Preface. In A. M. Beetz \& A. L. Podberscek (Eds.), Bestiality and Zoophilia: Sexual Relations with Animals. Ashland: Purdue University Press.

Beetz, A. M. (2008) Bestiality and Zoophilia: A Discussion of Sexual Contact with Animals. In F. R. Ascione (Ed.), The International Handbook of Animal Abuse and Cruelty (pp. 201-20): Purdue University Press.

Beirne, P. (2000). Rethinking Bestiality: Towards a Concept of Interspecies Sexual Assault. In A. L. Podberscek, E. S. Paul \& J. Serpell (Eds.), Companion Animals and Us (pp. 313-331). Cambridge: Cambridge University Press.

Bunzl, M. (1997). Outing as Performance/Outing as Resistance: A Queer Reading of Austrian (Homo)Sexualities. Cultural Anthropology, 12(1), 129-51. http://dx.doi.org/10.1525/can.1997.12.1.129

Butler, J. (1990). Gender Trouble: Feminism and the Subversion of Identity. New York: Routledge. Reprint.

Cassidy, R. (2009). Zoosex and Other Relationships with Animals. In D. Hastings \& F. Magowan (Eds.), Transgressive Sex: Subversion and Control in Erotic Encounters (pp. 91-112): Berghahn Books.

Cerrone, G. H. (1991). Zoophilia in a Rural Population: Two Case Studies. Journal of Rural Community Psychology, 12(1), 29-39. 
Davies, C. (1982). Sexual Taboos and Social Boundaries. American Journal of Sociology, 87, 1032-63.

Deckers, L., \& Kizer P. (1975). Humor and the Incongruity Hypothesis. The Journal of Psychology: Interdisciplinary and Applied, 90(2), 215-18. http://dx.doi.org/10.1080/00223980.1975.9915778

Dekkers, M. (1994). Dearest Pet: On Bestiality. Translated by P. Vincent. 2nd ed. New York: Verso. Reprint.

Douglas, M. (1966). Purity and Danger. London: Routledge \& Kegan Paul. Reprint.

Dundes, A. (1987). Cracking Jokes: Studies of Sick Humor Cycles and Stereotypes: Ten Speed Press. Reprint.

Emerson, J. P. (1969). Negotiating the Serious Import of Humor. Sociometry, 32(2), 169-81. http://dx.doi.org/10.2307/2786261

Finnis, J., \& Nussbaum M. (1993). Is Homosexual Conduct Wrong? A Philosophical Exchange. New Republic 20 (November).

Fromm, E. (1956). The Art of Loving. New York: Harper and Brothers Publishers. Reprint.

Fuss, D. (Ed.). (1996). Human, All Too Human. London: Routledge.

Grebowicz, M. (2010). When Species Meat: Confronting Bestiality Pornography. Humanimalia 1(2).

Gregersen, E. (1983). Sexual Practices: The Story of Human Sexuality. New York: Franklin Watts. Reprint.

Haraway, D. J. (2000). A Manifesto for Cyborgs: Science, Technology, and Socialist Feminism in the 1980's. In G. Kirkup, L. Janes, K. Woodward \& F. Hovenden (Eds.), The Gendered Cyborg (pp. 50-57). London: Routledge.

Kahn, R. (2011). For a Multiple-Armed Love: Ecopedagogy for a Posthuman Age. In C. S. Malott \& P. Bradley (Eds.), Critical Pedagogy in the Twenty-First Century: A New Generation of Scholars (pp. 109-32): Information Age Publishing.

Kirby, R., \& Corzine J. (1981). The Contagion of Stigma: Fieldwork among Deviants. Qualitative Sociology, 4(1), 3-20. http://dx.doi.org/10.1007/BF00987041

Leach, E. (1964). Anthropological Aspects of Language: Animal Categories and Verbal Abuse. In E.H. Lenneberg (Ed.), New Directions in the Study of Language (pp. 23-63). Cambridge: MIT Press.

Lee, R. M. (1993). Doing Research on Sensitive Topics. London: Sage. Reprint.

Miletski, H. (1999). Bestiality - Zoophilia: An Exploratory Study. Doctoral Dissertation, The Institute for Advanced Study of Human Sexuality.

Miletski, H. (2002). Understanding Bestiality and Zoophilia. Bethesda, MD: East-West Publishing LLC. Reprint.

Miletski, H. (2005). A History of Bestiality. In A. M. Beetz \& A. L. Podberscek (Eds.), Bestiality and Zoophilia: Sexual Relations with Animals (pp. 1-22). Ashland: Purdue University Press.

Miller, I. W. (1997). The Anatomy of Disgust: Harvard University Press. Reprint.

Nagel, T. (2002). Sexual Perversion. In A. Soble (Ed.), The Philosophy of Sex: Contemporary Readings (pp. 31-44) Boston: Rowman \& Littlefield Publishers.

Phelan, S. (1989). Identity Politics: Lesbian Feminism and the Limits of Community. Philadelphia: Temple University Press. Reprint.

Plummer, K. (1975). Sexual Stigma: An Interactionist Account. London: Routledge and Kegan Paul. Reprint.

Powell, C. (1988). A Phenomenological Analysis of Humour in Society. In C. Powell \& G. E. Paton (Eds.), Humour in Society: Resistance and Control (pp. 86-105). Basingstole: MacMillan.

Rozin, P., \& Fallon A. E. (1987). A Perspective on Disgust. Psychological Review, 94(1), 23-51. http://dx.doi.org/10.1037/0033-295X.94.1.23

Shell, M. (1986). The Family Pet. Representations 15(Summer):121-53.

Shir-Vertesh, D. (2012). Flexible Personhood: Loving Animals as Family Members in Israel. American Anthropologist, 114(3), 420-432. http://dx.doi.org/10.1111/j.1548-1433.2012.01443.x

Shir-Vertesh, D. (2008). 'Good to Love': Human-Animal Boundaries in Israel. Ph.D. Dissertation, Ben-Gurion University of the Negev.

Shir-Vertesh, D. (2006). Transspecies Sexual Attraction: Zoophilia and Human-Animal Boundaries. Animals and Society 30, Tel Aviv University. 
Singer, P. (2001). Heavy Petting. Nerve (www.nerve.com). March/April.

Taylor, T. (1996). The Prehistory of Sex. New York: Bantam Books. Reprint.

Troiden, R. R. (1987). Walking the Line: The Personal and Professional Risks of Sex Education and Research. Teaching Sociology, 15(3), 241-49.

Whitaker, M. P. (2004). Tamilnet.com: Some Reflections on Popular Anthropology, Nationalism, and the Internet. Anthropological Quarterly, 77(3), 469-498. http://dx.doi.org/10.1353/anq.2004.0034

Williams, C. J., \& Weinberg M. S. (2003). Zoophilia in Men: A Study of Sexual Interest in Animals. Archives of Sexual Behavior, 32(6), 523-35. http://dx.doi.org/10.1023/A:1026085410617

Wilson, S. M., \& Peterson L. C. (2002). The Anthropology of Online Communities. Annual Review of Anthropology, 31, 449-467. http://dx.doi.org/10.1146/annurev.anthro.31.040402.085436

\footnotetext{
${ }^{\mathrm{i}}$ Unless complemented by distress or interference with normal functioning on the part of the person, as other paraphilias not otherwise specified in The Diagnostic and Statistical Manual of Mental Disorders (DSM-IV, 1994; DSM-IV-TR, 2000).

${ }^{\text {ii }}$ Some cultures both past and present permit and even encourage sexual relations with animals in certain situations, such as the Kusai, the Masai, the Fez (Ford and Beach 1970 in: Dekkers 1994), and certain Native American tribes (Miletski 2002; 2005), among others.

iii The exact phrase in Hebrew is "tevel" - an abomination or perversion.

${ }^{\text {iv }}$ Both the man and the goat are not cartoon characters, but rather 'living' ones.

"The expression "goat" (ez) is a recurring slogan used in this company's commercials, indicating a burden or an errand, something to get rid of. The expression is also evocative of the Jewish scapegoat (See Author 2008).

${ }^{\text {vi }}$ Off is Poultry in Hebrew.

vii In Hebrew Slang “dafakti tarnegolet le'tzohora'im” can mean both "ate a chicken for lunch” and "screwed a chicken at lunch-time".

viii The Romanian and Russian word for chicken.
}

\section{(cc) EY}

This work is licensed under a Creative Commons Attribution 3.0 License. 